\title{
DETERMINAÇÃO DE CÁDMIO EM BIJUTERIAS ORIUNDAS DA CHINA
}

\author{
Ariane R. Pais ${ }^{a}$, Larissa N. Dina ${ }^{a}$, Evandro R. Alves ${ }^{b}$, Hélen C. de Rezendec, Luís A. da Silva e Valéria A. Alves ${ }^{\mathrm{a}, *}$ \\ aDepartamento de Química, Instituto de Ciências Exatas, Naturais e Educação, Universidade Federal do Triângulo Mineiro, $38064-$ \\ 200 Uberaba - MG, Brasil \\ bDepartamento de Engenharia de Alimentos, Instituto de Ciências Tecnológicas e Exatas, Universidade Federal do Triângulo \\ Mineiro, 38064-200 Uberaba - MG, Brasil \\ 'Unidade Acadêmica de Ciências Exatas, Universidade Federal de Goiás, 75805-190 Jataí - GO, Brasil
}

Recebido em 05/06/2018; aceito em 23/07/2018; publicado na web em 21/08/2018

\begin{abstract}
DETERMINATION OF CADMIUM IN LOW-COST JEWELRY FROM CHINA. This study aimed to determine cadmium in lowcost jewelry from China. In the qualitative test the sulfide was used as precipitating agent. Due to the strong interference of copper in qualitative analysis, this element was removed by chemical reaction or electrolysis. This removal was of paramount importance for the qualitative analysis of $\mathrm{Cd}^{2+}$. Quantification of $\mathrm{Cd}^{2+}$ was performed by means of atomic absorption spectrometry. The concentration of Cd was $\sim 30 \%(w / w)$ in one of the pieces. It is noteworthy that in a small universe of low-cost jewelry analyzed (four samples), such a high cadmium content found in one of them leads us to think that jewelry containing $\mathrm{Cd}$ are widespread among citizens. This work can be useful to approach the case study method for teaching Analytical Chemistry at the undergraduate level.
\end{abstract}

Keywords: case study; cadmium; low-cost jewelry; alloy; analytical chemistry.

\section{INTRODUÇÃO}

A articulação entre problemas reais e conhecimento científico, permitindo a proposição de novos experimentos (ou atividades) em química, é bastante impactante, considerando que os livros texto trazem essencialmente a fundamentação teórica, enquanto os artigos científicos especializados se utilizam da aplicação das técnicas analíticas em pesquisas científicas avançadas, muitas vezes não sendo de utilidade para fins didáticos em aulas em nível de graduação. ${ }^{1}$ Dessa forma, o método de estudo de caso pode se constituir numa alternativa interessante para a formação do estudante, enquanto graduando.

Conforme preconizado, um estudo de caso deve agregar o conhecimento científico aos aspectos sociais, econômicos, éticos e ambientais. ${ }^{2}$ No entanto, é rara a aplicação do método de estudo de caso nos cursos de Química. ${ }^{3}$ Por ocasião desse método de estudo, espera-se que os alunos entrem em contato com problemas reais e sejam agentes ativos no que se diz respeito ao seu aprendizado. ${ }^{1}$

A ideia de realizar esse trabalho foi devido à suspeita de fraude fiscal com relação às bijuterias oriundas da China, na qual alta concentração de cádmio foi encontrada em amostras das mesmas (em torno de $35 \%, \mathrm{~m} / \mathrm{m})$. ${ }^{4-6}$

É grande a quantidade de mulheres que usam bijuterias devido à grande facilidade em adquiri-las no comércio formal e informal, e pelo fato do preço ser bastante acessível. Ressalta-se que o problema se agravou no Brasil, onde não havia, até janeiro de 2016, uma legislação que dizia a respeito desse assunto, ou seja, sobre a quantidade de elementos potencialmente tóxicos na composição química de bijuterias. Recentemente o Brasil regulamentou o teor máximo permitido de cádmio e chumbo em bijuterias e joias, por meio da Portaria n. ${ }^{\circ}$ 43, de 22 de janeiro de 2016 do Instituto Nacional de Metrologia, Qualidade e Tecnologia - INMETRO, sendo que os teores máximos permitidos são de $0,01 \%$ e $0,03 \%$, respectivamente. ${ }^{7}$

Na União Europeia (UE) e nos Estados Unidos da América (EUA), onde existe legislação específica há alguns anos, a concentração permitida de cádmio é de $0,01 \%$ e $0,03 \%$, respectivamente. A

\footnotetext{
*e-mail: valeria.alves@uftm.edu.br
}

concentração de cádmio nas bijuterias do lote suspeito estava até dez mil vezes maior do que o permitido pela legislação vigente, nacional ou internacional.

Diante dessa informação, surgiram vários questionamentos, tais como: "Por quê na China essas peças são fabricadas com uma alta quantidade de cádmio na sua composição química? Será que as bijuterias que são comercializadas no Brasil também apresentam esses níveis de cádmio? Se o ser humano for exposto ao cádmio, por meio do contato cutâneo com esse tipo de acessório, quais os problemas de saúde acarretados?"

\section{O elemento cádmio}

O cádmio é um elemento químico pertencente ao grupo 12 da tabela periódica, possui número atômico 48 , massa atômica relativa 112,41 u e estado de oxidação principal $(+2)$; seus pontos de fusão e de ebulição são $321,07{ }^{\circ} \mathrm{C}$ e $766,87^{\circ} \mathrm{C}$, respectivamente, e densidade $8,64 \mathrm{~g} \mathrm{~cm}^{-3}$. Foi descoberto pelo químico alemão Friedrich Stromeyer, em 1817.

O cádmio ocorre naturalmente por meio do intemperismo das rochas, erupções vulcânicas, erosão do solo e queimadas florestais, sendo as erupções vulcânicas as maiores fontes de emissão de cádmio na atmosfera. A China e a França são países com o solo altamente poluído pelo cádmio, sendo as prováveis causas da contaminação relacionadas com a ação antropogênica, resultado da mineração e fundição de minérios de zinco, ferro, chumbo e cobre. ${ }^{8-11}$

O cádmio não é um elemento essencial; geralmente é encontrado no meio ambiente em baixas concentrações, associado ao zinco, chumbo ou cobre. As principais formas de exposição ao cádmio são: cutânea, pulmonar e gastrintestinal. A absorção através da pele não é uma via significativa de entrada de cádmio, em condições normais apenas cerca de $0,5 \%$ de cádmio é absorvido pela pele. ${ }^{12}$

$\mathrm{O}$ cádmio é um elemento de baixa abundância, encontrado comumente em minerais sulfurados, especialmente o $\mathrm{ZnS}$, e em menor escala em outros minerais de $\mathrm{Zn}$, como a $\mathrm{ZnCO}_{3}$, e silicatos. Há também evidências de uma afinidade com a matéria orgânica; alguns tipos de carvão, turfa e petróleo bruto contêm níveis relativamente 
altos de $\mathrm{Cd}$, o que pode ser devido à adsorção seletiva e à complexação por compostos húmicos. ${ }^{13}$

As principais aplicações do cádmio são as baterias de $\mathrm{Ni}-\mathrm{Cd}$ (79\%), os pigmentos de cádmio (11\%), os estabilizadores de cádmio (2\%), os revestimentos de cádmio (7\%), as ligas de cádmio e os componentes eletrônicos de cádmio, como o telureto de cádmio (CdTe) $(1 \%) .{ }^{12,14-16}$

Nos seres vivos, o cádmio pode afetar vários órgãos, como o fígado, rins, pulmões, ovários, ossos, entre outros. ${ }^{12}$

Por ser muito tóxico, o cádmio pode afetar o crescimento das plantas, reduzir a fotossíntese e alterar as atividades metabólicas e enzimáticas das mesmas. ${ }^{17,18}$

Devido à fácil visualização de alterações cromossômicas das cebolas nas fases de divisão celular, desde 1938 esses organismos têm sido bastante utilizados em testes de laboratório para estudos de efeitos citogenéticos causados por várias substâncias. No caso de toxicidade, são observadas restrições no crescimento longitudinal das raízes, incluindo efeitos como raízes irregulares. ${ }^{19} \mathrm{O}$ cádmio, em pequenas concentrações, tem sido utilizado para investigar o seu efeito tóxico no crescimento de cebolas (Allium cepa), uma vez que a taxa de inibição do crescimento (TIC) da raiz mostra o efeito da toxicidade do metal. Na presença de íons cádmio, a TIC das raízes chegou a $70 \%$ em $2,0 \mathrm{mg} \mathrm{L}^{-1} .^{20}$

Os padrões estabelecidos pelo Conselho Nacional do Meio Ambiente (CONAMA) da qualidade da água para o consumo humano e para o lançamento de efluentes, em valores máximos, são de 0,005 e $0,2 \mathrm{mg} \mathrm{L}^{-1}$, respectivamente. A legislação faz menção apenas à concentração total do elemento, muito embora os efeitos tóxicos de uma espécie difiram em relação à forma química em que a mesma se encontra. ${ }^{21,22}$

\section{Estado da arte}

Os recentes trabalhos publicados na literatura relacionados com a expansão da contaminação por cádmio em amostras ambientais, ${ }^{23-25}$ em animais ${ }^{26,27}$ e em alimentos, ${ }^{28,29}$ e considerando também a possibilidade de bijuterias contaminadas com esse elemento químico, representam um alerta para a sociedade moderna.

A industrialização e a queima de combustíveis fósseis resultaram num rápido aumento de emissões de cádmio no meio ambiente e, consequentemente, elevou os níveis de cádmio nos animais e vegetais. Importante destacar a aplicação do cádmio na produção de pigmentos de tom amarelo. A manipulação e o desgaste com o tempo são fontes de contaminação. Investigações realizadas no quadro "Flores em um vaso azul", de Vincent van Gogh, mostraram a oxidação do $\mathrm{CdS}$ a $\mathrm{CdSO}_{4} \cdot \mathrm{H}_{2} \mathrm{O} \cdot{ }^{30}$

A literatura especializada carece de pesquisa sobre a presença do elemento cádmio em bijuterias de baixo custo. Os autores Guney e Zagury publicaram artigos relatando a presença de cádmio em bijuterias de baixo custo adquiridas no Canadá. Em duas publicações eles analisaram os teores de cádmio utilizando a espectrometria de emissão óptica com plasma indutivamente acoplado (ICP-OES) e observaram valores acima do máximo permitido pela legislação do Canadá. ${ }^{31-34}$

Pouzar et al. em cooperação com a Inspecção Ambiental República Checa analisaram peças de bijuterias de baixo custo por espectrometria de fluorescência de raios $\mathrm{X}$ por energia dispersiva (ED-XRF) e também encontraram teores de cádmio muito acima dos valores máximos permitidos pela legislação da UE. ${ }^{35}$

Weidenhamer et al. analisou por espectrometria de fluorescência de raios-X (XRF) várias amostras de bijuterias de baixo custo adquiridas no comércio varejista de diferentes regiões dos EUA. Eles também obervaram valores acima do máximo permitido pela legislação do EUA. ${ }^{36}$
Inverstigando a realidade das bijuterias de baixo custo no Brasil, Ferreira et al. utilizaram a voltametria de pulso diferencical. Os autores observaram que 1/3 das amostras analisadas apresentaram concentrações acima do máximo permitido pela legislação do Brasil. A escassez de estudos com bijuterias de baixo custo importadas sugere a importância da pesquisa e a necessidade de expansão das investigações científicas em nosso país. ${ }^{37,38}$

Considerando a enorme extensão territorial do Brasil e que bijuterias contaminadas podem estar espalhadas por todo o país, a responsabilidade pelo controle e fiscalização é das autoridades competentes, mas a ciência também tem seu papel nesse processo, e tem real importância quando está incumbida com assuntos que dizem respeito aos aspectos sociais, econômicos, éticos e ambientais que permeiam a sociedade.

Nesse contexto, o presente trabalho com bijuterias de baixo custo visa propor o método de estudo de caso para aprendizagem em Química Analítica (Qualitativa e Instrumental), em que o aluno, mediado pelo professor, depara-se com um problema real e utiliza a literatura especializada em Química Analítica para se posicionar diante do mesmo. ${ }^{39-44}$ É esperado que, nesse processo de ensino-aprendizagem, o aluno utilize conteúdos de Química Analítica Qualitativa (reações químicas para $\mathrm{Fe}$ e $\mathrm{Cu}$ e a marcha analítica do subgrupo do cobre), e de Análise Instrumental (eletrogravimetria e espectrometria de absorção atômica).

A investigação apresenta como objetivo a identificação da presença de cádmio em bijuterias oriundas da China e comercializadas na cidade de Uberaba-MG. O desenvolvimento da pesquisa baseou-se nas seguintes etapas: aquisição de bijuterias oriundas da China, e comercializadas em lojas da cidade de Uberaba-MG; classificação das bijuterias adquiridas quanto ao tipo de liga metálica (ferrosa ou de cobre); preparo das amostras das bijuterias e realização de ensaios químicos para identificação de cádmio e utilização da eletrogravimetria e da espectrometria de absorção atômica para quantificação do teor de cobre e de cádmio nas bijuterias, respectivamente.

\section{PARTE EXPERIMENTAL}

Foram adquiridas bijuterias comercializadas em duas lojas diferentes da cidade de Uberaba-MG, denominadas neste trabalho por A e B. As amostras passaram por um procedimento de limpeza, foram devidamente guardadas e identificadas. Para a limpeza das mesmas utilizou-se o método já publicado, que consistiu em fazer a imersão das peças em hexano, depois foram levadas ao banho de ultrassom durante 5 minutos e, por fim, foram expostas ao ambiente para secar. ${ }^{41}$ As bijuterias analisadas são identificadas na Tabela 1; a Figura 1S, disponível no Material Suplementar, mostra as peças (bijuterias) adquiridas.

Tabela 1. Identificação das bijuterias analisadas

\begin{tabular}{cccc}
\hline $\begin{array}{c}\text { Código } \\
\text { da Peça }\end{array}$ & $\begin{array}{c}\text { Loja de } \\
\text { Aquisição }\end{array}$ & $\begin{array}{c}\text { Código } \\
\text { da Peça }\end{array}$ & $\begin{array}{c}\text { Loja de } \\
\text { Aquisição }\end{array}$ \\
\hline $01-00$ & A & $07-00$ & B \\
$02-00$ & A & $08-00$ & B \\
$03-00$ & A & $09-00$ & B \\
$04-00$ & A & $09-01$ & B \\
$05-00$ & A & $09-02$ & B \\
$06-00$ & B & & \\
\hline
\end{tabular}

\section{Classificação das bijuterias quanto ao tipo de liga}

Foram realizados dois procedimentos para a identificação das ligas, um para as ligas de ferro e outro para ligas de cobre. ${ }^{41}$ A Figura 
$2 \mathrm{~S}$ do Material Suplementar apresenta uma fotografia ilustrativa da dissolução de uma amostra de bijuteria, a qual é representada pela equação química (1). Os ácidos utilizados para dissolução das amostras de bijuterias foram o ácido clorídrico concentrado (no caso de ligas de $\mathrm{Fe}$ ) ou o ácido nítrico $6 \mathrm{~mol} \mathrm{~L}^{-1}$ (no caso de ligas de $\mathrm{Cu}) \cdot{ }^{41} \mathrm{Em}$ ambos os casos houve dissolução completa das amostras; as soluções das amostras de cobre apresentaram cor azul. O Esquema 1 mostra os detalhes experimentais realizados para tal classificação.

$$
3 \mathrm{Cu}_{(s)}+2 \mathrm{NO}_{3(a q)}^{-}+8 \mathrm{H}_{(a q)}^{+} \stackrel{\text { calor }}{\longrightarrow} 3 \mathrm{Cu}_{(a q)}^{2+}+2 \mathrm{NO}_{(g)}+4 \mathrm{H}_{2} \mathrm{O}_{(l)}
$$

As equações químicas (2) e (3) resumem as reações do Fe e do $\mathrm{Cu}$, respectivamente: ${ }^{43}$

$$
\begin{aligned}
& \mathrm{Fe}_{(a q)}^{3+}+6 \mathrm{SCN}_{(a q)}^{-} \rightleftharpoons\left[\mathrm{Fe}(\mathrm{SCN})_{6}\right]_{(a q)}^{3-} \\
& \mathrm{Cu}_{(a q)}^{2+}+4 \mathrm{NH}_{3(a q)} \rightleftharpoons\left[\mathrm{Cu}\left(\mathrm{NH}_{3}\right)_{4}\right]_{(a q)}^{2+}
\end{aligned}
$$

A Figura 3S, disponível no Material Suplementar, apresenta fotografias representativas dos ensaios qualitativos realizados para a classificação das bijuterias, bem como os nomes e as estruturas dos íons complexos formados.

\section{Determinação de cádmio}

Foram realizados testes qualitativos para identificar a possível presença de cádmio nas bijuterias classificadas como sendo de cobre, ou que contêm esse elemento químico, uma vez que, segundo a literatura, ${ }^{41}$ apenas as ligas de cobre poderiam conter cádmio. Dessa forma, as ligas de ferro não foram incluídas na identificação de cádmio.
Para a identificação do cádmio, o agente precipitante utilizado foi o íon sulfeto, que precipita o cádmio em meio ácido, na forma de sulfeto de cádmio, um sólido amarelo, de acordo com a equação (4). ${ }^{43}$

$$
C d_{(a q)}^{2+}+S_{(a q)}^{2-} \rightleftharpoons C d S_{(s)}
$$

Os potenciais interferentes nessa identificação são o cobre, o cobalto, o níquel e o mercúrio. ${ }^{41}$ De acordo com a literatura ${ }^{45}$ a identificação do cádmio na solução da amostra é feita conforme mostrado no Esquema 2. Esse procedimento foi seguido e, em caso de presença de cádmio, ocorreu o aparecimento de um precipitado de cor amarela, confirmando a presença do elemento. ${ }^{45}$

As equações químicas envolvidas na Etapa II do Esquema 2 são dadas a seguir: ${ }^{45}$

$$
\begin{gathered}
\mathrm{Cu}_{(a q)}^{2+}+\mathrm{CH}_{2} \mathrm{OH}-\mathrm{CHOH}-\mathrm{CH}_{2} \mathrm{OH}_{(a q)}+2 \mathrm{OH}_{(a q)}^{-} \rightleftharpoons \mathrm{CH}_{2} \mathrm{OH}-\mathrm{CHO}-\mathrm{CH}_{2} \mathrm{O}_{(a q)}+2 \mathrm{H}_{2} \mathrm{O}_{(q)} \\
\mathrm{Cd}_{(a q)}^{2+}+2 \mathrm{OH}_{(a q)}^{-} \rightleftharpoons \mathrm{Cd}(\mathrm{OH})_{2(s)}
\end{gathered}
$$

A reação química que ocorre na Etapa II do Esquema 2 é aquela dada pela equação química (5). Sugere-se consultar o artigo de Andrade e Alvim, ${ }^{46}$ o qual apresenta o esquema simplificado para a separação e identificação dos cátions do subgrupo do cobre, em escala semi-micro.

Sabe-se que o cobre é um potencial interferente nessa análise, podendo mascarar a identificação do cádmio na amostra, caso não seja separado adequadamente (como mostrado no Esquema 2). Isso ocorre devido à formação de um precipitado de cor preta, o sulfeto de cobre, CuS. Uma outra rota analítica alternativa é remover o cobre antes da realização do ensaio qualitativo para cádmio, utilizando a

(a)
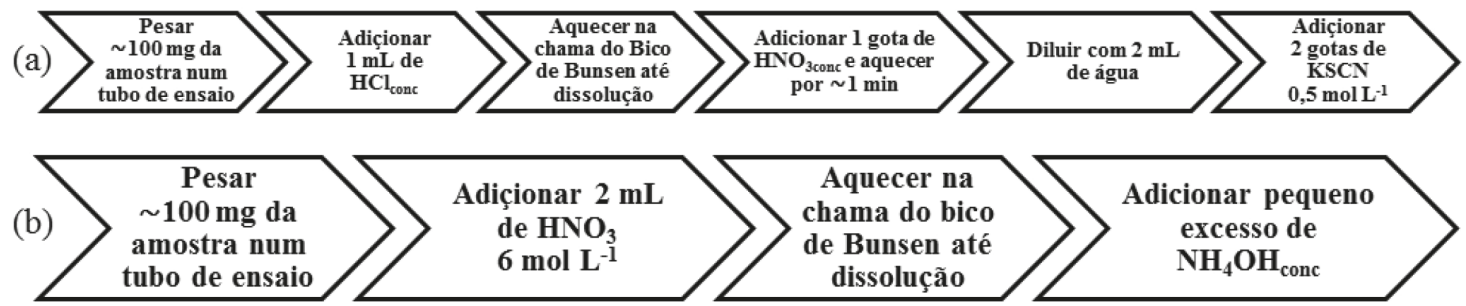

Aquecer na chama do bico de Bunsen até dissolução

Esquema 1. Etapas realizadas para classificação das bijuterias quanto ao tipo de liga. (a) Liga de ferro; (b) liga de cobre

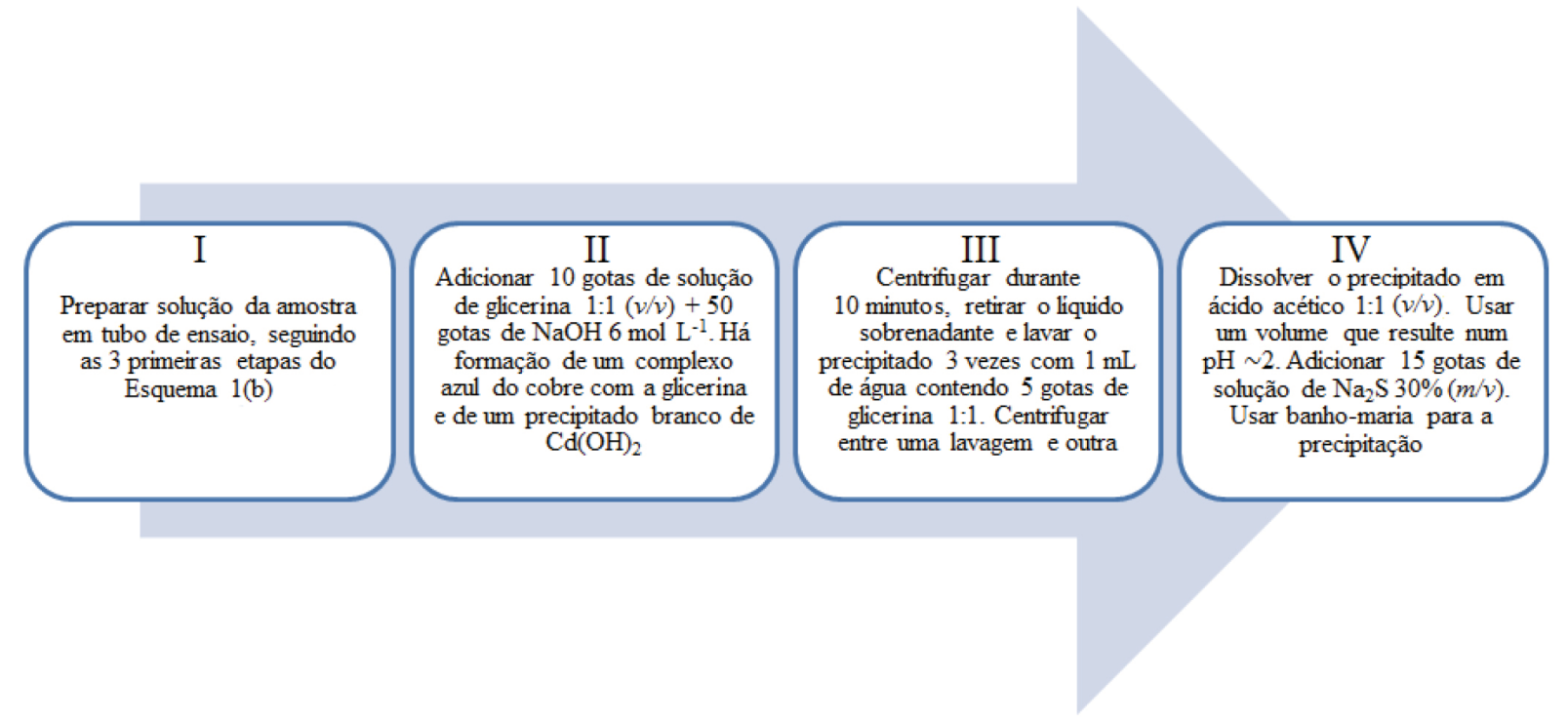




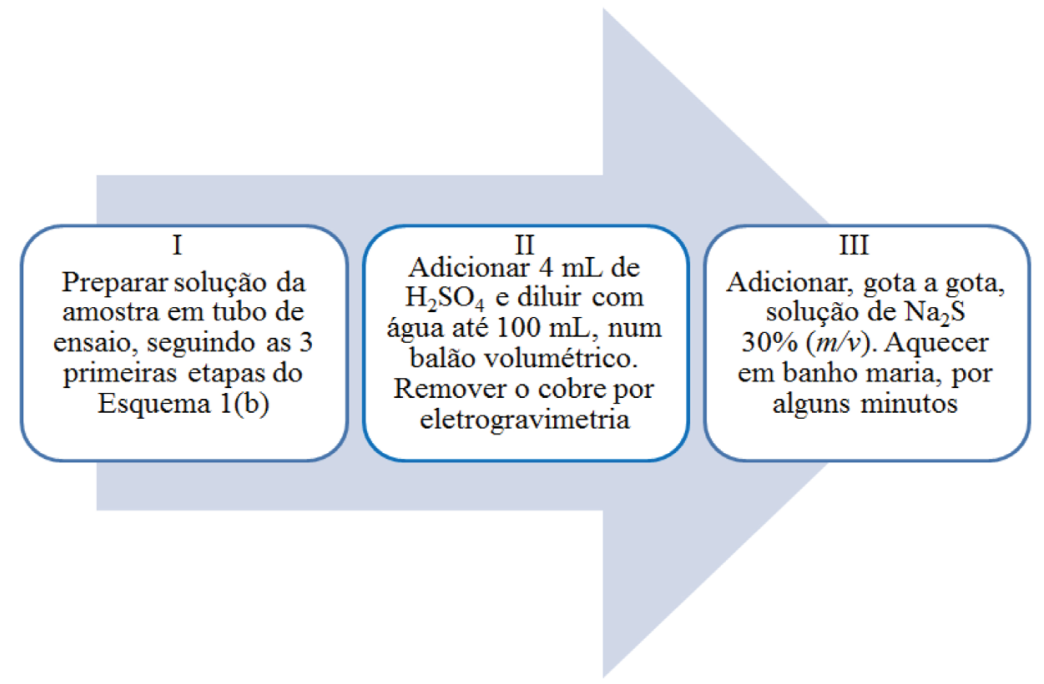

Esquema 3. Etapas realizadas para determinação de cádmio nas amostras de bijuterias (Esquema alternativo ao Esquema 2. Nesse caso, o cobre é removido por eletrogravimetria)

análise eletrogravimétrica, a qual pode ser seguida caso o estudo esteja sendo realizado por alunos que estejam cursando a disciplina Química Analítica Instrumental.

O Esquema 3 mostra a nossa proposta para (a possível) identificação de cádmio em amostras de bijuterias de cobre; essa rota envolve menos etapas relação ao Esquema 2. Em caso de presença de cádmio ocorre o aparecimento de um precipitado de cor amarela, confirmando a presença do elemento na amostra, devido à equação (4). ${ }^{41,43}$

\section{Análise eletrogravimétrica das bijuterias de cobre}

As eletrólises das soluções das amostras devem ser realizadas antes do teste qualitativo para cádmio porquê o cobre é um potencial interferente no referido teste. Essas análises foram realizadas por duas razões: i. remoção do $\mathrm{Cu}^{2+}$; e ii. determinação quantitativa de $\mathrm{Cu}^{2+}$. O procedimento seguido encontra-se publicado; ${ }^{40} \mathrm{o}$ aparato utilizado é ilustrado na Figura 4S do Material Suplementar. Ressalta-se que nas condições em que a eletrólise do $\mathrm{Cu}^{2+}$ foi realizada (solução de ácido sulfúrico + ácido nítrico), o $\mathrm{Cd}^{2+}$ não foi eletrodepositado simultaneamente, já que para isso ocorrer necessita-se de solução de alcalina de cianeto. ${ }^{42}$ Além disso, os valores dos potenciais padrão de redução dos sistemas redox $\mathrm{Cd}^{2+} / \mathrm{Cd}_{(\mathrm{s})}$ e $\mathrm{Cu}^{2+} / \mathrm{Cu}_{(\mathrm{s})}$ são $+0,337 \mathrm{~V}$ e $-0,403 \mathrm{~V},{ }^{42}$ respectivamente, o que permite uma deposição seletiva do cobre. Apesar das concentrações de $\mathrm{Cd}^{+2}$ e de $\mathrm{Cu}^{2+}$ nas soluções das amostras certamente desviarem-se da concentração de $1 \mathrm{~mol} \mathrm{~L}^{-1}$ (concentração das condições padrão), os potenciais são suficientemente diferentes para garantir que apenas o cobre seja depositado no cátodo de platina. De acordo com Skoog et al., a eletrólise a potencial de célula constante é capaz de separar esses dois íons, já que os íons cobre são mais facilmente reduzíveis do que os íons cádmio. Além disso, esse último é mais difícil de ser reduzido do que o íon hidrogênio ou o íon nitrato, presentes no meio (e que atuam como despolarizantes, ou seja, impedem que o cátodo atinja um potencial suficientemente negativo para depositar os íons cádmio). ${ }^{42}$

Para a quantificação do teor de cobre nas bijuterias o eletrodo de rede de platina utilizado foi pesado antes e após a eletrólise. Realizou-se o cálculo da \% de cobre $(\mathrm{m} / \mathrm{m})$ na amostra, utilizando-se a equação 1 .

$$
\% C u=\frac{\left(m^{\prime}-m\right)}{p} \times 100
$$

Em que: m'é a massa do eletrodo após o experimento, em $g$; $\mathrm{m}$ é a massa do eletrodo antes do experimento, em $g$; $\mathrm{P}$ é a massa da amostra, em $g$.

Como alternativa para as instituições de ensino que não dispõem de aparato eletroquímico para realizar a eletrogravimetria para remover o cobre, é possível realizar a separação do cobre por reação química, conforme procedimento da marcha analítica, ${ }^{45,46}$ conforme também foi realizado neste trabalho e apresentado no Esquema 2.

\section{Quantificação do cádmio nas bijuterias por espectrometria de absorção atômica}

No caso do cádmio ter sido identificado nas amostras de bijuterias à base de cobre, ou mesmo de ter-se ficado na dúvida sobre a presença deste elemento, utilizou-se a espectrometria de absorção atômica para determinar a concentração de cádmio na solução da amostra.

A quantificação do cádmio foi realizada utilizando um espectrômetro de absorção atômica com chama, equipado com lâmpada de deutério para correção do sinal de fundo, da Agilent Technologies Spectra AA220 (Santa Clara, CA, USA). Como fonte de radiação utilizou-se lâmpada de descarga de catodo oco de cádmio Varian (Angilent). Os parâmetros instrumentais utilizados seguiram as recomendações do fabricante e são apresentados na Tabela 2.

Tabela 2. Parâmetros instrumentais recomendados pelo fabricante para a determinação de cádmio

\begin{tabular}{lc}
\hline Parâmetro & Condição estabelecida \\
\hline Comprimento de onda (nm) & 228,8 \\
Resolução Espectral (nm) & 0,2 \\
Vazão de ar $\left(\mathrm{L} \mathrm{min}^{-1}\right)$ & 13,5 \\
Vazão de Acetileno $\left(\mathrm{L} \mathrm{min}^{-1}\right)$ & 2,0 \\
\hline
\end{tabular}

Para a preparação das soluções das amostras pesou-se 100 mg de amostra e adicionou-se $2 \mathrm{~mL}_{\text {de }} \mathrm{HNO}_{3} 6 \mathrm{~mol} \mathrm{~L}^{-1}$. Aqueceu-se o tubo de ensaio na chama de um bico de Bunsen até a completa dissolução da amostra; transferiu-se a mesma para um balão volumétrico de $25,00 \mathrm{~mL}$ e completou-se o volume com água destilada. Preparou-se também um branco, transferindo-se $2 \mathrm{~mL}^{\text {de }} \mathrm{HNO}_{3} 6 \mathrm{~mol} \mathrm{~L}^{-1}$ para um balão volumétrico de $25,00 \mathrm{~mL}$ e completando-se o volume até a sua marca de calibração, com água destilada.

Foram realizadas duas curvas de calibração, uma para as soluções 
das amostras das peças 01-00; 04-00 e 07-00 e outra para as peças 09-00; 09-01 e 09-02, sendo que no caso da peça 09-00 realizou-se medidas em triplicata (para as demais amostras, foi preparada somente uma replicata). A realização de duas curvas de calibração foi necessária devido ao fato que no caso das soluções das amostras das peças 09-00; 09-01 e 09-02, as mesmas eram muito concentradas em cádmio, havendo a necessidade de diluir 500 vezes para a realização das medidas.

\section{RESULTADOS E DISCUSSÃO}

\section{Classificação das bijuterias quanto ao tipo de liga}

Mediante a realização dos testes qualitativos, as bijuterias puderam ser classificadas quanto ao tipo de liga (ferrosa ou de cobre). Os resultados obtidos são apresentados na Tabela 3.

Tabela 3. Classificação das ligas

\begin{tabular}{ccc}
\hline Código da Peça & $m_{\text {amostra pesada }} / \mathrm{g}$ & Tipo de Liga \\
\hline $01-00$ & 0,240 & $\mathrm{Cu}$ \\
$02-00$ & 0,179 & $\mathrm{Fe}$ \\
$03-00$ & 0,130 & $\mathrm{Fe}$ \\
$04-00$ & 0,287 & $\mathrm{Cu}$ \\
$05-00$ & 0,183 & $\mathrm{Fe}$ \\
$06-00$ & 0,499 & $\mathrm{Fe}$ \\
$07-00$ & 0,500 & $\mathrm{Cu}$ \\
$08-00$ & 0,150 & $\mathrm{Fe}$ \\
$09-00$ & 0,204 & $\mathrm{Cu}$ \\
\hline
\end{tabular}

Verifica-se que, das nove peças analisadas, quatro são ligas de cobre e cinco são ferrosas. Segundo Muller ${ }^{41}$ o cádmio possivelmente seria encontrado em baixa concentração ou até como elemento-traço nas ligas de cobre. Por isso, nesse trabalho não são apresentados resultados para as bijuterias cuja matriz era uma liga ferrosa.

\section{Determinação de cádmio}

Após a classificação das ligas, realizou-se os testes qualitativos para as ligas contendo cobre na sua composição química, utilizando-se duas metodologias: i. determinação de cádmio via marcha analítica proposta por Baccan et al..$^{45}$ (veja Esquema 2) e ii. remoção de cobre por eletrólise e reação direta com sulfeto de sódio, $\mathrm{Na}_{2} \mathrm{~S} 30 \%(\mathrm{~m} / \mathrm{v})$ (veja Esquema 3). As análises qualitativas foram realizadas para as soluções das amostras 01-00, 04-00, 07-00 e 09-00. Resultados representativos dos testes qualitativos são mostrados nas Figuras 1 a 3. A amostra de referência (Figura 4) foi preparada com água + ácido nítrico + nitrato de cádmio + sulfeto de sódio.

A Figura 1 apresenta o resultado da análise a partir da marcha analítica proposta por Baccan et al. ${ }^{45}$ para determinação de cádmio na solução da amostra da peça 09-00. A Figura 2 apresenta os resultados da adição de sulfeto de sódio diretamente na solução eletrolisada da amostra, pois todo o cobre, o principal interferente, foi removido por eletrogravimetria.

A partir da Figura 2 verifica-se que, no caso das amostras 01-00 e 04-00, a cor do precipitado foi de um leve amarelado. Diferentemente, a peça 09-00 apresentou a formação de um precipitado amarelo intenso, indicando um resultado positivo para cádmio.

A Figura 3 mostra o ensaio qualitativo para a amostra da peça 07-00; nesse caso não realizou-se a remoção do cobre da solução da amostra, por eletrogravimetria. A adição de sulfeto de sódio

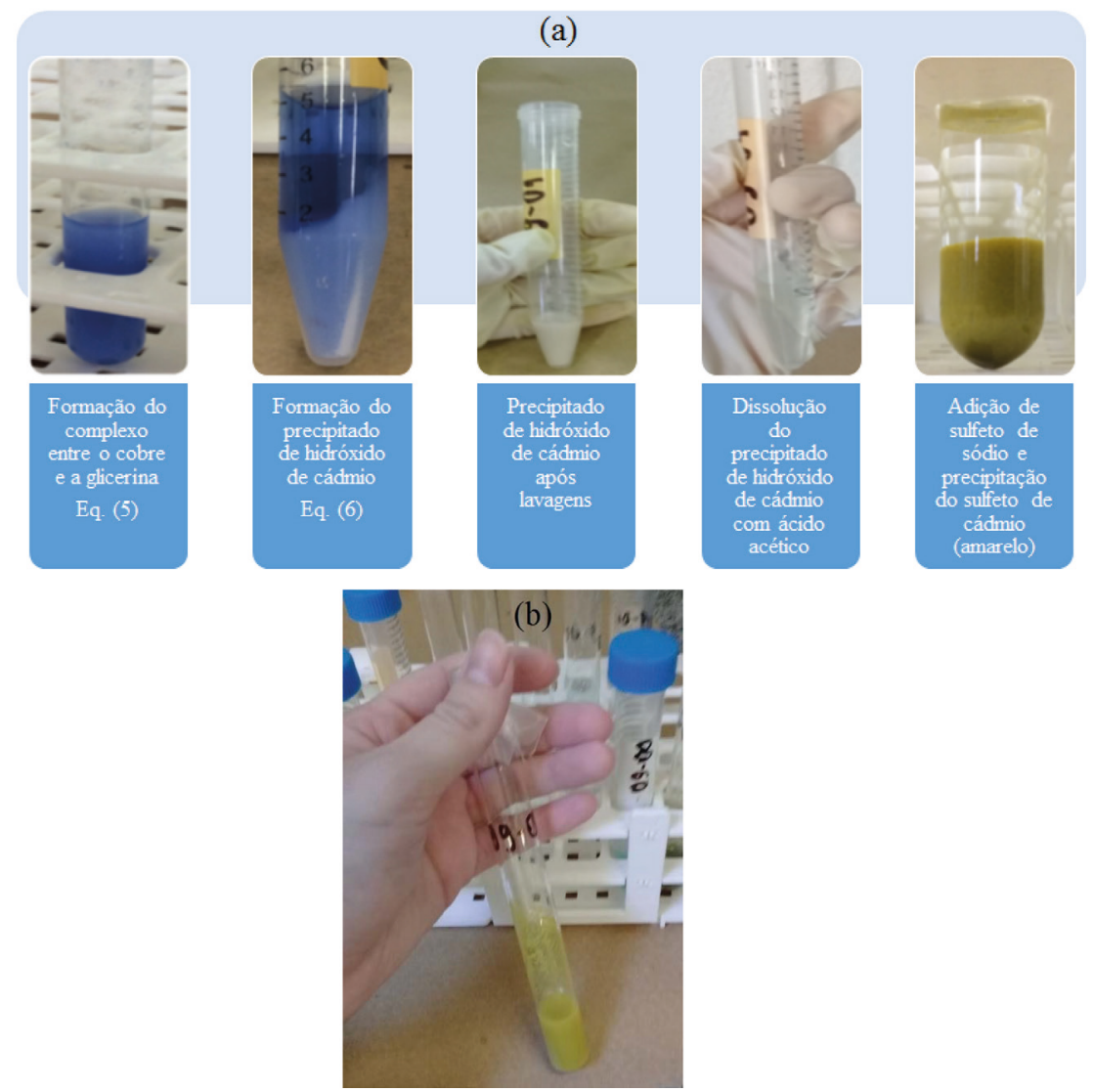

Figura 1. Testes qualitativos segundo a metodologia proposta por Baccan et al. ${ }^{45}$ (adaptada) para determinação de cádmio na solução da amostra da peça 09-00. A última fotografia da sequência de etapas mostrada em (a) e a fotografia mostrada em (b) referem-se ao mesmo teste 

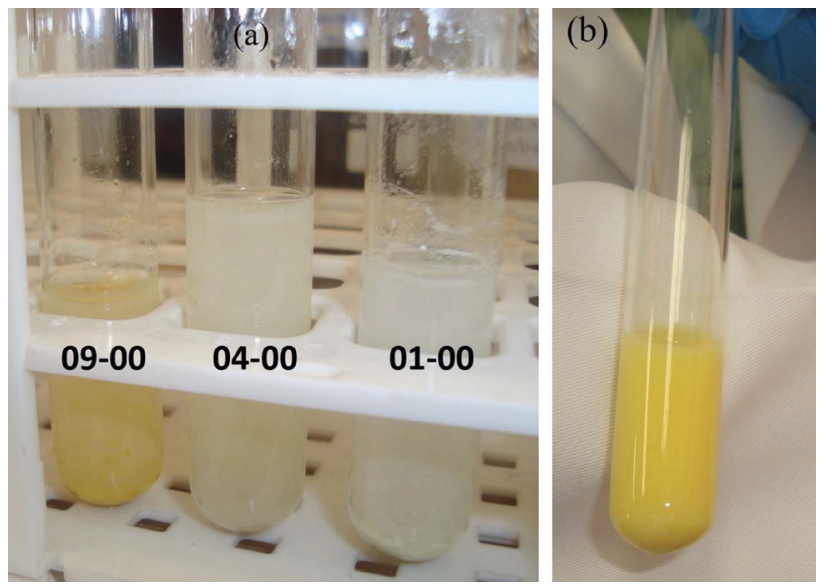

Figura 2. Testes qualitativos para soluções das amostras das peças (bijuterias), após remoção do cobre por eletrogravimetria e reação direta com $\mathrm{Na}_{2} \mathrm{~S} 30 \%$ ( $/ \mathrm{v}$ ) (veja Esquema 3). (a) amostras 01-00; 04-00 e 09-00; e (b) amostra 09-00

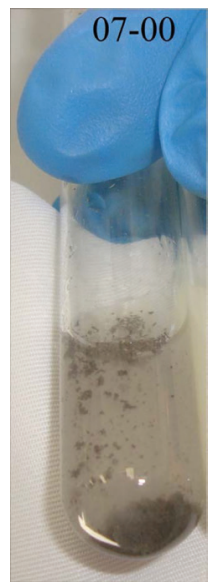

Figura 3. Teste qualitativo para identificação de cádmio na solução da amostra da peça 07-00, na presença de cobre e reação direta com $\mathrm{Na}_{2} \mathrm{~S} 30 \%(\mathrm{~m} / \mathrm{v})$

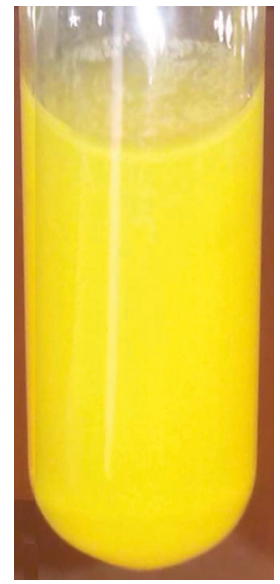

Figura 4. Fotografia da amostra de referência, preparada com nitrato de cádmio em meio ácido e reação direta com $\mathrm{Na}_{2} \mathrm{~S} 30 \%(\mathrm{~m} / \mathrm{v})$

diretamente à solução da amostra [sem remoção de cobre por eletrogravimetria ou separação por reação química] mostra que este (o cobre) forma um precipitado preto (de $\mathrm{CuS}$ ), que intefere na identificação do cádmio.

Ambas as metodologias, representadas nas Figuras 1 e 2, geraram uma intensa coloração amarela (de CdS), somente no caso da solução da amostra da bijuteria 09-00, indicando um teste positivo para cádmio. Interessantemente, a metodologia mostrada no Esquema 3 é uma alternativa àquela da marcha analítica proposta por Baccan et al. ${ }^{45}$ mostrada no Esquema 2, na qual vários reagentes são necessários, tais como glicerina, hidróxido de sódio e ácido acético. Por outro lado, é necessário dispor do aparato eletroquímico (fonte de alimentação e dois eletrodos de platina). Cabe aos analistas avaliar qual metodologia é mais condizente com a sua realidade, já que as duas funcionam muito bem para identificação de cádmio em amostras de bijuterias de cobre.

As Tabelas 4 e 5 apresentam as sínteses das observações realizadas nos ensaios qualitativos das soluções das amostras.

Tabela 4. Síntese das observações dos ensaios qualitativos para cádmio das soluções das amostras das peças 04-00, 07-00 e 09-00, via marcha analítica proposta por Baccan et al. ${ }^{45}$ (Esquema 2)

\begin{tabular}{ccc}
\hline Código da peça & $\begin{array}{c}\text { Remoção de cobre por } \\
\text { reação química? }\end{array}$ & $\begin{array}{c}\text { Formação de precipitado } \\
\text { amarelo? }\end{array}$ \\
\hline $01-00$ & Sim & Levemente amarelado \\
$04-00$ & Sim & Levemente amarelado \\
$07-00$ & Sim & Levemente amarelado \\
$09-00$ & Sim & Amarelo intenso \\
\hline
\end{tabular}

Tabela 5. Síntese das observações dos ensaios qualitativos para cádmio, após remoção de cobre das soluções das amostras por eletrogravimetria (Esquema 3)

\begin{tabular}{ccc}
\hline Código da peça & $\begin{array}{c}\text { Remoção de cobre por } \\
\text { eletrólise? }\end{array}$ & $\begin{array}{c}\text { Formação de precipitado } \\
\text { amarelo? }\end{array}$ \\
\hline $01-00$ & Sim & Levemente amarelado \\
$04-00$ & Sim & Levemente amarelado \\
$07-00$ & Sim & Levemente amarelado \\
$09-00$ & Sim & Amarelo intenso \\
\hline
\end{tabular}

Como o teste qualitativo para cádmio foi positivo para a amostra da peça 09-00, visto que observou-se uma coloração amarela intensa, bem próxima da cor esperada (veja Figura 4), realizou-se os testes qualitativos para mais duas amostras dessa mesma peça. Esses novos testes qualitativos também confirmaram a presença de cádmio.

Baseado nesses resultados para a peça 09-00, resolveu-se comprar mais duas peças iguais à peça 09-00, na mesma loja $\mathrm{B}$, agora denominadas 09-01 e 09-02, gerando a triplicata. Novamente, os testes qualitativos foram positivos para cádmio, no caso dessas duas novas peças. Vale ressaltar que a peça 09-00 foi comprada em janeiro de 2014, já as peças 09-01 e 09-02 foram compradas em maio de 2014, ou seja, quatro meses depois.

\section{Análise eletrogravimétrica das bijuterias à base de cobre}

As análises eletrogravimétricas foram realizadas antes do teste qualitativo para cádmio, isso porque, como mostrado na Figura 3, o cobre é um forte interferente no teste qualitativo, podendo mascarar a identificação do cádmio na amostra, caso exista. A porcentagem de cobre encontrada nas amostras, via eletrogravimetria, das peças analisadas é dada na Tabela 6. Os dados apresentados foram calculados conforme a equação 1 .

Verifica-se que as amostras onde foram encontrados altos teores de cobre, apresentaram também uma coloração quase imperceptível no teste qualitativo para cádmio. No entanto, para as amostras das três peças iguais (09-00; 09-01 e 09-02) obteve-se teores bem menores de cobre. Apesar disso, houve forte evidência da presença de cádmio no teste qualitativo. 
Tabela 6. Porcentagem de cobre encontrada nas peças, por eletrogravimetria

\begin{tabular}{ccc}
\hline Código da Peça & $m_{\text {amostra pesada }} / \mathrm{g}$ & $\% \mathrm{de} \mathrm{Cu}(\mathrm{m} / \mathrm{m})$ \\
\hline $01-00$ & 0,0997 & 67,10 \\
$04-00$ & 0,0983 & 68,77 \\
$07-00$ & 0,0937 & 61,26 \\
$09-00$ & 0,1091 & 8,70 \\
$09-01$ & 0,1032 & 13,37 \\
$09-02$ & 0,1237 & 6,71 \\
\hline
\end{tabular}

Quantificação do cádmio nas bijuterias por espectrometria de absorção atômica

Os resultados obtidos por meio das medidas de espectrometria de absorção atômica são apresentados na Tabela 7. Os resultados obtidos confirmam o que foi verificado a partir dos ensaios qualitativos. De fato, as peças 09-00; 09-01 e 09-02 apresentam cádmio na sua composição química. E, o mais agravante, é que o teor de cádmio é bastante alto $(\sim 30 \%, \mathrm{~m} / \mathrm{m})$, induzindo a pensar que é possível que essas peças possam estar relacionadas com aquele lote de bijuterias oriundo da China, mencionado no início do artigo. Ou ainda, pode se tratar de outro lote contaminado, que porventura tenha entrado no país sem que se notasse tal fato (alto teor de cádmio nas bijuterias). Isso nos induz a pensar que esse tipo de bijuteria, com alto teor de cádmio, pode estar mais difundido entre nós do que imaginamos.

A outra peça que apresentou cádmio na sua composição química foi a 01-00, mas o teor é bem mais baixo, 0,0036\%, ou seja, da ordem de 10.000 vezes mais baixo (estando dentro do permitido pela legislação atual). Segundo a técnica de espectrometria de absorção atômica, as amostras 04-00 e 07-00 não apresentaram cádmio na sua composição química, muito embora ficou-se em dúvida quanto à presença de cádmio, a partir do teste qualitativo, no caso da amostra da peça 04-00 (que resultou num precipitado com um leve tom de amarelo).

Conforme mencionado anteriormente, no Brasil, a legislação que estabelece o limite da concentração de cádmio em bijuterias em joias data de janeiro de 2016. As amostras analisadas nesse trabalho foram adquiridas no ano de 2014. No entanto, algumas bijuterias (anéis semelhantes aos analisados nesse trabalho e denominados 09-00, 09-01 e 09-02), foram adquiridas no ano de 2017, após a publicação da portaria do INMETRO, mas ainda não tinham sido analisadas. As análises por Espectrometria de Absorção Atômica de amostras desses anéis, realizadas recentemente e ainda não publicadas, mostraram que as concentrações de cádmio estão bastante acima daquela permitida pela legislação vigente (máximo de $0,01 \%, \mathrm{~m} / \mathrm{m}$ ), e os valores situam-se próximos daqueles obtidos para as peças 09-00, 09-01 e 09-02, o que mostra que o problema da contaminação de bijuterias de baixo custo por cádmio ainda persiste no Brasil.

\section{CONCLUSÕES}

A partir dos resultados obtidos encontrados nesse trabalho, especialmente no que se refere às peças (bijuterias) 09-00, 09-01 e 09-02, "contaminadas" com cádmio, apresenta-se como hipótese que essas são provenientes do lixo de eletroeletrônicos que a China produz (por exemplo, baterias de níquel-cádmio). Ou seja, para se livrar desse material tóxico, a China fabrica essas bijuterias e exporta para outros países. Visto que essas bijuterias (peças) têm um custo muito baixo, torna-se bastante atraente para mulheres e meninas, em Uberaba/MG, e em todo o país. O valor das peças que apresentaram altos teores de cádmio, $\sim 30 \%(\mathrm{~m} / \mathrm{m})$, é de R $\$ 3,00$. Seu custo é muito baixo, porém o cádmio presente na sua composição química pode causar sérios danos à saúde. Vale ressaltar que esses estudos foram realizados em 2014, quando ainda não havia no Brasil nenhuma legislação que regulamentasse sobre o controle da entrada delas no país e nem sobre o teor de cádmio permitido; isso só ocorreu em janeiro de 2016. Estudos recentes em nosso laboratório apontam que bijuterias contaminadas com cádmio continuam circulando no País.

Foi proposto um procedimento alternativo para identificação de cádmio, no que tange a interferência do cobre; isso foi feito realizando-se eletrólise da solução da amostra de bijuteria para a remoção completa do cobre da mesma. Nosso procedimento funciona tão bem quanto o procedimento da marcha analítica proposto por Baccan et al., que elimina a interferência do cobre por meio de reação química com a glicerina em meio alcalino, o qual também foi utilizado nesse trabalho.

Vale ressaltar que alguns autores propõem uma marcha analítica que utiliza cianeto para mascarar a interfência do cobre. Os autores advertem que o uso de $\mathrm{CN}^{-}$deve ser evitado, especialmente em meio ácido, devido a problemas de toxicidade (ocorre a formação de ácido cianídrico, HCN, que é muito tóxico se inalado!). Portanto, recomenda-se evitar a utilização desse procedimento nas aulas de Química Analítica.

Esse trabalho constitui-se em uma ótima sugestão para estudo de caso em disciplinas de Química Analítica em cursos de graduação. O professor pode suscitar, a partir desse tema, as questões sociais, econômicas, éticas e ambientais que o permeiam, além da rica parte conceitual da química que pode ser explorada pelos alunos, permitindo que esses apreendam novos conhecimentos, ou os consolidem, na tentativa de resolver um problema real (contaminação de cádmio em bijuterias).

Tabela 7. Resultados das análises das amostras de bijuterias por Espectrometria de Absorção Atômica

\begin{tabular}{|c|c|c|c|c|c|}
\hline Amostra & Reta Analítica & Faixa linear $\left(\mathrm{mg} \mathrm{L}^{-1}\right)$ & $\mathrm{Cd}\left(\mathrm{mg} \mathrm{L}^{-1}\right)$ & $\mathrm{Cd}\left(\mathrm{mg} \mathrm{L}^{-1}\right)$ & $\mathrm{Cd}(\% \mathrm{~m} / \mathrm{m})$ \\
\hline 01-00 & \multirow{3}{*}{$\begin{array}{c}y=0,15548 x-0,00263 \\
R^{2}=0,99563\end{array}$} & \multirow{3}{*}{0 a 0,50} & 0,0884 & - & 0,0036 \\
\hline 04-00 & & & $<$ L.D. & - & $<$ L.D. \\
\hline 07-00 & & & <L.D. & - & $<$ L.D. \\
\hline 09-00/I & \multirow{5}{*}{$\begin{array}{c}\mathrm{y}=0,23087 \mathrm{x}-0,02271 \\
\mathrm{R}^{2}=0,99759\end{array}$} & \multirow{5}{*}{0 a 3,00} & $1,4878^{*}$ & 743,91 & 28,48 \\
\hline 09-00/II & & & $1,7510^{*}$ & 875,49 & 30,27 \\
\hline 09-00/III & & & $1,9067 *$ & 953,37 & 33,95 \\
\hline 09-01 & & & $2,1799 *$ & 1089,95 & 33,64 \\
\hline 09-02 & & & $1,9729 *$ & 986,47 & 35,23 \\
\hline
\end{tabular}

*Diluída 500 vezes. 


\section{MATERIAL SUPLEMENTAR}

As Figuras 1S a 4S estão disponíveis em http://quimicanova.sbq. org.br, na forma de arquivo PDF, com acesso livre.

\section{AGRADECIMENTOS}

A presente publicação faz parte de um projeto de pesquisa em colaboração com os membros da Rede Mineira de Química (RQ-MG), apoiado pela FAPEMIG (Processo CEX-RED-00010-14).

À FAPEMIG, pela bolsa de IC de L. N. Dina.

\section{REFERÊNCIAS}

1. Grigoletto, T. L. B.; Fuzari, B. H. C.; Andrade, A. R.; Campos, M. L. A. M.; Gerlach, R. F.; dos Santos, J. E. T.; Quim. Nova 2012, 35, 1995.

2. Sá, L. P.; Francisco, C. A.; Queiroz, S. L.; Quim. Nova 2007, 30, 731.

3. Sá, L. P.; Queiroz, S. L; Estudo de casos no ensino de química, Editora Átomo: Campinas, 2009.

4. http://g1.globo.com/fantastico/noticia/2013/11/teste-mostra-alto-nivelde-cadmio-em-bijuterias-vindas-da-china.html, acessada em agosto 2018.

5. http://g1.globo.com/fantastico/noticia/2013/11/laudo-alerta-para-altaconcentracao-de-substancia-toxica-em-bijuterias.html, acessada em agosto 2018 .

6. http://www.justica.gov.br/noticias/nota-conjunta-da-anvisa-e-senacon, acessada em Maio 2018.

7. http://www.inmetro.gov.br/legislacao/rtac/pdf/RTAC002383.pdf, acessada em Maio 2018

8. Sterckeman, T.; Douay, F.; Proix, N.; Fourrier, H.; Environ. Pollut. 2000, 107, 377.

9. Waterlot, C.; Bidar, G.; Pelfrêne, A.; Roussel, H.; Fourrier, H.; Douay, F.; Pedosphere 2013, 23, 143.

10. Shen, F.; Liao, R.; Ali, A.; Mahar, A.; Guo, D.; Li, R.; Sun, X.; Awasthi, M. K.; Wang, Q.; Zhang, Z.; Ecotoxicol. Environ. Saf. 2017, 139, 254.

11. Chen, H.; Teng, Y.; Lu, S.; Wang, Y.; Wang, J.; Sci. Total Environ. 2015, $512 / 513,143$.

12. https://www.atsdr.cdc.gov/toxprofiles/tp5.pdf, acessada em agosto 2018.

13. http://weppi.gtk.fi/publ/foregsatlas/text/Cd.pdf, acessada em agosto 2018.

14. Morrow, H. Em Kirk-Othmer Encyclopedia of Chemical Technology; Kirk-Othmer, ed.; $5^{\text {th }}$ ed., John Wiley \& Sons: New York, 2001, vol. 4, p. 471.

15. https://www.cadmium.org/cadmium-applications, acessada em agosto 2018.

16. http://metalpedia.asianmetal.com/metal/cadmium/application.shtml, acessada em agosto 2018.

17. Benavides, M. P.; Gallego, S. M.; Tomaro, M. L.; Br. J. Plant Physiol. 2005, 17, 21.

18. Dias, M. C.; Monteiro, C.; Pereira, J. M.; Correia, C.; Gonçalves, B.; Santos, C.; Acta Physiologiae Plantarum 2013, 35, 1281.
19. Ribeiro, I. A.; Dissertação de mestrado, Universidade de São Paulo, Brasil.

20. Sousa, W. J.; Alves, V. A.; Anais do $57^{\circ}$ Congresso Brasileiro de Química, Gramado, Brasil, 2017.

21. http://www.mma.gov.br/port/conama/res/res05/res35705.pdf, acessada em agosto 2018.

22. http://www.mma.gov.br/port/conama/res/res11/res43011.pdf, acessada em agosto 2018.

23. Brett, C. M. A.; Fungaro D. A.; J. Braz. Chem. Soc. 2000, 11, 298.

24. Muñoz, C.; Zúñiga, M.; Arancibia; J. Braz. Chem. Soc. 2010, 21, 1688.

25. Wu, H.; Liao, Q.; Chillrud, S. N.; Yang, Q.; Huang, L.; Bi, J.; Yan, B.; Sci. Rep. 2016, 6, article number 29989.

26. http://agencia.fapesp.br/pesquisa_analisa_metais_toxicos_encontrados_ em_caranguejos/19066/, acessada em agosto 2018.

27. Alkmim Filho, J. F.; Germano, A.; Dibai, W. L. S.; Vargas, E. A.; Melo, M. M.; Food Sci. Technol. 2014, 34, 110.

28. Vulcano, I. R. C.; Silveira, J. N.; Alvarez-Leite, E. M.; Rev. Bras. Cienc. Farm. 2008, 44, 425.

29. Ke, S.; Cheng, X.-Y.; Zhang, N.; Hu, H.-G.; Yan, Q.; Hou, L.-L.; Sun, X.; Chen, Z.-N.; Environ. Monit. Assess. 2015, 187, 408.

30. Snickt, G. V. D.; Janssens, K.; Dik, J.; Nolf, W.; Vanmeert, F.; Jaroszewicz, J.; Cotte, M.; Falkenberg, G.; Loeff, L. V. D.; Anal. Chem. 2012, 84, 10221.

31. Guney, M.; Zagury, G. J.; Environ. Sci. Technol. 2014, 48, 1238.

32. Guney, M.; Zagury, G. J.; Environ. Sci. Technol. 2013, 47, 5921.

33. Guney, M.; Zagury, G. J.; Environ. Sci. Technol. 2012, 46, 4265.

34. Guney, M.; Zagury, G. J.; Environ. Sci. Technol. 2011, 45, 3819.

35. Pouzar, M.; Zvolská, M.; Jarolím, O.; Vavrušová, L. A.; Int. J. Environ. Res. Public Health 2017, 14, 520.

36. Weidenhamer, J. D.; Miller, J.; Guinn, D.; Pearson, J.; Environ. Health Perspect. 2011, 119, 1029.

37. https://issuu.com/fapemig/docs/mfc_65_, acessada em agosto 2018.

38. Ferreira, T. P.; de Sousa, R. A.; Lowinsohn, D. Anal. Methods 2016, 8, 8028.

39. Harris, D. C.; Explorando a Química Analítica; 4a. ed., LTC: Rio de Janeiro, 2011.

40. Kobal Júnior, J.; Sartório, L.; Manual de Análise Instrumental, 1ª ed., Moderna: São Paulo, 1978.

41. Mueller, H; Souza, D.; Química Analítica Qualitativa Clássica, Edifurb: Blumenau, 2010.

42. Skoog, D. A.; West, D. M.; Holler, F. J.; Crouch, S. R.; Fundamentos de Química Analítica, Thomson: São Paulo, 2006.

43. Vogel, A. I. Química Analítica Qualitativa; Gimeno, A., trad.; Svehla, G., rev.; Mestre Jou: São Paulo, 1981.

44. Holler, F. J.; Skoog, D. A.; Crouch, S. R.; Princípios de Análise Instrumental, $6^{\mathrm{a}}$ ed., Bookman: Porto Alegre, 2009.

45. Baccan, N.; Godinho, O. E. S.; Aleixo, L. M.; Stein, E.; Introdução à Semimicroanálise Qualitativa. 7ª ed., UNICAMP: Campinas, 1997.

46. http://chemkeys.com/br/wp-content/themes/chemkeysbr/articleI. php?u=cWFiLTMtYS1mb3JtYWNhby1kby1xdWltaWNv, acessada em agosto 2018. 